SHORT REPORT

\title{
Risk of selected birth defects by maternal residence close to power lines during pregnancy
}

\author{
K G Blaasaas, T Tynes, R T Lie
}

Occup Environ Med 2004;61:174-176. doi: 10.1136/oem.2002.006239

Aims: To evaluate selected birth outcomes from a published Norwegian cohort study in a nested case-control design with improved exposure data.

Methods: Two controls matched for sex, year of birth, and municipality were selected randomly for children with the following defects: central nervous system (CNS) defects, cardiac defects, respiratory system defects, oesophageal defects, and clubfoot. The distances between maternal addresses, during pregnancy, and power lines were obtained from maps mainly of scale 1:5000. The magnetic fields in the residences were estimated based on distance, current, voltage, and configuration.

Results: The highest increased risks were seen for hydrocephalus (OR 1.73, 95\% Cl 0.26 to 11.64 ) and for cardiac defects (OR 1.54, 95\% Cl 0.89 to 2.68).

Conclusion: This study does not support the hypothesis that residential exposure to electromagnetic fields from power lines causes any of the investigated outcomes.

S everal studies of possible effects of low frequency electromagnetic fields on human health have been carried out. ${ }^{1}$ Most attention has been given to the occurrence of cancer. A number of studies regarding reproductive outcomes have been reviewed by Robert, ${ }^{2}$ but represent no convincing evidence that electromagnetic field exposure of pregnant women or their partners is associated with reproductive outcomes. Two recent studies from California suggest an effect of maximum field exposure on the risk of fetal loss. ${ }^{3}{ }^{4}$ However, most previous studies are quite small and would not have enough statistical power to detect effects on risks of specific birth defects. Animal models do not indicate that low frequency electromagnetic field exposure has serious reproductive effects. ${ }^{5}$

In an earlier Norwegian study of reproductive outcomes among workers in occupations exposed to $50 \mathrm{~Hz}$ magnetic fields, increased risks of selected central nervous system defects were found ${ }^{6}$ Indications of increased risks of clubfoot and respiratory system defects were also seen. Another cohort study $^{7}$ indicated an increased risk of oesophageal defects and reduced risks of cardiac and respiratory defects among children whose mothers lived close to power lines during pregnancy, but no effects were seen on the risk of neural tube defects. This study was based on distance measured through geographical information systems (GIS). However, a study comparing GIS based distance measurements and measurements made on maps mainly of scale 1:5000 and on site measurements showed that map based distances correlated better with on site measures than GIS based data. ${ }^{8}$ Based on this fact, we have assessed the risk of central nervous system defects, clubfoot, oesophageal defects, cardiac defects, and respiratory system defects by maternal residential exposure to magnetic fields from power lines in a nested case-control study within the previously reported cohort. Our motivation for choosing these sites was the findings in the two previous Norwegian cohort studies. ${ }^{67}$ In the present study we used data based on measurements on maps, mainly of scale 1:5000, to determine distances between Norwegian residences and power lines and to calculate the magnetic fields in the houses.

\section{METHOD}

The Medical Birth Registry of Norway comprises all Norwegian births with at least 16 weeks of gestation. Notification is compulsory, and is performed by midwives within the first week after birth. Any diagnosis available at that time should be reported. We used the registry as our source of ascertainment. Since the registry only captures diagnoses within the first week after birth, ascertainment is assumed to be poorer for internal defects such as cardiac defects than for external defects like spina bifida with an estimated ascertainment of $80 \%{ }^{9}$

The birth defects included in the analyses were: central nervous system (CNS) defects, cardiac defects, respiratory system defects, oesophageal defects, and clubfoot. These outcomes were selected based on results of earlier investigations regarding magnetic fields and reproductive outcomes. ${ }^{6} 7$ Children could be registered with up to three different types of malformations. We did not consider multiple defects as a separate category. However, when considering spina bifida and hydrocephalus, those with a recorded anencephalus were not included. Similarly, children with hydrocephalus in combination with spina bifida were not counted as hydrocephalus cases.

The Norwegian person identification number is recorded for child and mother of all births in the registry. Through the mothers' personal identification numbers, Statistics Norway identified all mothers registered in The Medical Birth Registry of Norway who had lived in a corridor around each power line, broad enough to include all potentially exposed houses, on 1 January 1980 or later. The corridor ranged from $25 \mathrm{~m}$ on each side of a $25 \mathrm{kV}$ line to $300 \mathrm{~m}$ on each side of a $420 \mathrm{kV}$ line. In the period 1986 to 1997, exact new addresses were updated on 1 January annually. Due to the lack of exact address information in the period 1981 to 1985 , births during this period were excluded. A woman entered the cohort the first year she was registered in a residence within the corridor and left when she moved out. The child was regarded as exposed if the mother lived in an exposed residence for more than half the pregnancy.

For every child in the corridor registered in The Medical Birth Registry of Norway with one of the defects to be included in the analyses, born in 1980 or between 1 January 1986 and 31 August 1997, two controls matched for sex, year of birth, and municipality were selected randomly. The

Abbreviations: GIS, geographical information systems; CNS, central nervous system 
Main messages

- The Medical Birth Registry of Norway provides a good opportunity to evaluate birth outcomes in offspring of mothers residing near high voltage power lines.

- Residential exposure to magnetic fields had no impact on the outcomes evaluated.

distances between residence and power line were measured on maps, mainly of scale 1:5000. Maps have earlier been shown to be better correlated with actual distances than GIS based distances ${ }^{8}$ as used in our previous publication. ${ }^{7}$ Information on currents of each power line was obtained from the different power companies. By use of a computer program (Teslaw) developed at SINTEF Energy, Norway, estimations of magnetic fields in the residences under study were performed. The program presents the result as $\mu \mathrm{T}$ root mean square magnetic field strength. This is the sum of the vectors for the individual conductor in a given situation integrated over one period. The calculations took account of height of towers, distance between phases, ordering of phases, distance between the power line and the house, and average load on the power line. Distance to the power lines was defined as the distance from the closest corner of the house to the mid-point between the outer phases of a line. A residence was regarded as exposed if the estimated magnetic field was $0.1 \mu \mathrm{T}$ or above.

Odds ratios (OR) for the exposed compared to the unexposed with $95 \%$ confidence intervals (CI) were obtained from conditional logistic regression for 1 to 2 matched data adjusting for mother's age and highest family education. The analyses were carried out for CNS defects, heart defects, respiratory defects, clubfoot, and oesophageal defects. Significance levels were set to $5 \%$ for each hypothesis test, and no attempts were made to adjust for multiple comparisons. The statistical software used was EGRET for Windows 2.0.31. ${ }^{10}$

\section{RESULTS}

Of a total of 744324 births in Norway in the period of investigation, 128680 were within the corridor from whom we found 465 cases and selected 930 controls.

The highest ORs were found for hydrocephalus and cardiac defects (table 1). Lowest ORs were found for spina bifida and oesophageal defects.

\section{DISCUSSION}

This investigation showed no significant increased or decreased risk for the defects evaluated.
Policy implications

- The present results do not call for any efforts towards mothers living close to power lines.

Comparing these results with our findings in the earlier residential cohort study, ${ }^{7}$ the excess risk of oesophageal defects and the reduced risks of cardiac and respiratory defects was not reproduced in the present study. Neither do the present results support earlier findings regarding maternal occupational exposure and birth defects. ${ }^{6}$

For spina bifida, oesophageal defects, and clubfoot there is a shift from increased to decreased risk, in the present study compared to the previous residential cohort investigation, although only the risk of oesophageal defect was significant in the previous study. For hydrocehalus and cardiac defects we observed a shift from decreased to increased risk, significant only for cardiac defects in the previous study. For respiratory system defects, the reduced risk was closer to unity compared to the previous study. The distance measurements in this study are more accurate ${ }^{8}$ than in the previous study. We therefore consider the results in this study more reliable.

Information of the mothers' addresses only once a year in the study period was one important limitation in this study. Another critical problem was the limited number of cases and subsequent limited statistical power.

Residential exposure based on calculated magnetic fields from power lines only with no personal measurements, may have introduced some exposure misclassification, but a previous dosimeter study among children living close to a power line in Norway, showed that the magnetic fields from the line is the major source of exposure. ${ }^{11}$ This should be the case for adults too. In comparison with other countries, like Sweden, the contribution of ground currents to magnetic fields in homes is minor in Norway because of a different grounding system.

The Norwegian birth registry only includes birth defects identified at the maternity ward in the hospital during the first week after birth. The majority of birth defects are probably detected shortly after birth. However, defects diagnosed later, such as cardiac defects, are less likely to be detected and might therefore be seriously underreported in the registry.

In the present population based, nested case-control study, we took advantage of the population registration system in Norway. Furthermore, by defining the study population as adults who had lived in geographical areas crossed by high voltage power lines, we could assume these lines to be the main source of exposure. The design made it possible to

Table 1 Odds ratios of selected birth defects by maternal residential exposure to magnetic fields above $0.1 \mu \mathrm{T}$ in Norway 1980-1997

\begin{tabular}{|c|c|c|c|c|c|c|}
\hline \multirow[b]{2}{*}{ Category of birth defects } & \multicolumn{3}{|l|}{ Crude } & \multicolumn{3}{|l|}{ Adjusted* } \\
\hline & No. cases & OR & $95 \% \mathrm{Cl}$ & No. cases & OR & $95 \% \mathrm{Cl}$ \\
\hline All CNS defects & 51 & 0.87 & 0.34 to 2.17 & 49 & 0.86 & 0.33 to 2.29 \\
\hline Anencephalus & 13 & 1.00 & 0.16 to 6.42 & 12 & 1.09 & 0.15 to 8.08 \\
\hline Spina bifida & 19 & 0.43 & 0.08 to 2.31 & 19 & 0.60 & 0.10 to 3.47 \\
\hline Hydrocephalus & 14 & 1.88 & 0.39 to 8.92 & 13 & 1.73 & 0.26 to 11.64 \\
\hline Cardiac defects & 103 & 1.54 & 0.89 to 2.67 & 102 & 1.54 & 0.89 to 2.68 \\
\hline Respiratory system defects & 40 & 0.84 & 0.30 to 2.34 & 39 & 0.79 & 0.28 to 2.23 \\
\hline Oesophageal defects & 12 & 0.29 & 0.04 to 2.32 & 10 & 0.41 & 0.03 to 5.15 \\
\hline Clubfoot & 270 & 0.84 & 0.57 to 1.23 & 269 & 0.82 & 0.56 to 1.21 \\
\hline
\end{tabular}


control for factors associated with area of residence and socioeconomic status.

In conclusion, this study does not support the hypothesis that residential exposure to electromagnetic fields from power lines causes any of the investigated outcomes.

\section{Authors' affiliations}

K G Blaasaas, National Institute of Occupational Health, Oslo, Norway

T Tynes, Norwegian Radiation Protection Authority, Østerås, Norway

R T Lie, Section for Epidemiology and Medical Statistics, Department of

Public Health and Primary Health Care, University of Bergen, Norway

The Research Council of Norway supported this work

Correspondence to: K G Blaasaas, Norwegian Armed Forces, Joint Medical Services, Bygning 0028A, N-2058 Sessvollmoen, Norway; kblaasaas@mil.no

Accepted 27 March 2003

\section{REFERENCES}

1 Portier CJ, Wolfe M, eds. NIEHS Working Group Report. Assessment of health effects from exposure to power-line frequency electric and magnetic fields. NIH Publication No.983981. Bethesda: National Institute of Health.
2 Robert E. Intrauterine effects of electromagnetic fields (low frequency, midfrequency RF, and microwave): review of epidemiologic studies. Teratology 1999;59:292-8.

3 Lee GM, Neutra RR, Hristova L, et al. A nested case-control study of residential and personal magnetic field measures and miscarriages. Epidemiology 2002;13:21-31

4 Li DK, Odouli R, Wi S, et al. A population-based prospective cohort study of personal exposure to magnetic fields during pregnancy and the risk of miscarriage. Epidemiology 2002;13:9-22.

5 Brent RL. Reproductive and teratologic effects of low-frequency electromagnetic fields: a review of in vivo and in vitro studies using animal models. Teratology 1999;59:261-86.

6 Blaasaas KG, Tynes T, Irgens $\AA$, et al. Risk of birth defects by parental exposure to $50 \mathrm{~Hz}$ electromagnetic fields: a population based study. Occup Environ Med 2002;52:92-7.

7 Blaasaas KG, Tynes T, Lie RT. Risk of birth defects by residence near power lines; a population-based study. Epidemiology 2003;14:95-8.

8 Blaasaas KG, Tynes T. Comparison of three different ways of measuring distance between residences and high voltage power lines. Bioelectromagnetics 2002;23:288-91.

9 Lie RT, Heuch I, Irgens LM. Maximum likelihood estimation of the proportion of congenital malformations using double registration systems. Biometrics 1994;50:433-44.

10 EGRET for Windows. Software for the analysis of biomedical and epidemiological studies. User manual. Cambridge, MA: CYTEL Software Corporation, 2001

11 Vistnes AI, Ramberg GB, Bjornevik LR, et al. Exposure of children to residential magnetic fields in Norway: is proximity to power lines an adequate predictor of exposure? Bioelectromagnetics 1997;18:47-57. 


\section{PostScript}

\section{LETTERS}

\section{Occupational exposure of midwives to nitrous oxide on delivery suites}

In our opinion, the article "Occupational exposure of midwives to nitrous oxide on delivery suites"1 is in need of some remarks.

In the paper a serious problem seems to be the presence of nitrous oxide in samples collected at the beginning of the shift.

Many years ago, when $\mathrm{N}_{2} \mathrm{O}$ in urine was first evaluated, we frequently observed "uncommon" concentration of $\mathrm{N}_{2} \mathrm{O}$ in urine of exposed and unexposed subjects. The phenomenon was kept under control and disappeared when urine samples were treated with a small quantity of $\mathrm{H}_{2} \mathrm{SO}_{4}(0.2 \mathrm{ml})$. For this reason, we suggested the following: " “... Approximately $10 \mathrm{ml}$ of urine were collected from all the subjects at the end of the exposure period in $120 \mathrm{ml}$ gastight glass vials with airtight plugs. Caps were rapidly replaced in the vials to prevent any significant loss of $\mathrm{N}_{2} \mathrm{O}$. The vials contained $0.2 \mathrm{ml}$ sulfuric acid in order to avoid the in vitro production of $\mathrm{N}_{2} \mathrm{O}$ (probably due to microflora activity). ${ }^{3}$...".

Another point we consider very important is that the subjects must void the bladder rapidly in areas known to be free of nitrous oxide, otherwise a significant contamination of samples can occur.

In conclusion, we think that among the simple precautions that should be taken to avoid significant errors (avoiding collection of urine samples in places contaminated with $\mathrm{N}_{2} \mathrm{O}$, carrying out collection rapidly, and using airtight collection vials in order to avoid any major loss of dissolved anaesthetic), one point should be emphasised in view of its importance: storage of urine before analysis can produce an endogenous formation of $\mathrm{N}_{2} \mathrm{O}$ originating from the oxidation processes of the nitrogen compounds present in biological liquids. Experiments performed to study this phenomenon have shown that the process is inhibited if the urine is kept acid. If, as a precaution, a few drops of strong acid are added to each collection vial before urine samples are collected, neoformation of nitrous oxide will be avoided and the urine samples may then be stored as long as required prior to the analysis.

M Imbriani

Università degli Studi di Pavia Dipartimento di Medicina Preventiva, Occupazionale e di Comunità, Pavia, Italy

S Ghittori, L Maestri

Labs-Meia, Fondazione Salvatore Maugeri IRCCS, via Ferrata, 8, Pavia, Italy

Correspondence to: Dr S Ghittori; sghittori@fsm.it doi: 10.1136/oem.2003.012534

\section{References}

1 Henderson KA, Matthews IP, Adisesh A, et al. Occupational exposure of midwives to nitrous oxide on delivery suites. Occup Environ Med 2003;60:958-61.

2 Imbriani M, Ghittori S, Pezzagno G, et al. Nitrous oxide in urine as biological index of exposure in operating room personnel. Appl Ind Hyg 988;3:223-7.

3 World Health Organisation (WHO). Health hazards from nitrates in drinking water Environmental Health 1. Report on a WHO meeting. Copenhagen, 1985:33-4.

\section{Author's reply}

Professor Imbriani and colleagues report experiments which showed that endogenous formation of $\mathrm{N}_{2} \mathrm{O}$ was inhibited if urine is kept acid. The convenience of adding $0.2 \mathrm{ml}$ of sulphuric acid to vials recommends its routine use in practice and we do not disagree with this recommendation.

The likelihood that the pre-shift urine measurements which we reported arise from this phenomenon rather than other factors should be judged in the light of the following considerations:

- All pre-shift urine samples were collected in areas free of nitrous oxide.

- The period between sample collection and deposit in a freezer was approximately the same for each sample. Despite this 24 midwives had zero $\mathrm{N}_{2} \mathrm{O}$ in their pre-shift samples and 22 had non-zero values, of whom 12 had very high values.

- The period between deposit in a freezer and analysis varied between samples but biological activity should not occur in the freezer.

I Matthews

Department of Epidemiology, Statistics and Public Health, University of Wales College of Medicine, Heath Park, Cardiff CF14 4XN, UK; matthewsip@cf.ac.uk

\section{The evidence for workplace counselling is in Medline}

Henderson et al point out the increasing approval of counselling as an effective intervention to treat or prevent the effects of stress at work by British judges, although they could use expert advice on this matter. ${ }^{1}$ In reaction to this development, they pose the rhetorical question: where to find evidence on the effectiveness of counselling. In stead of answering this question they grasp the opportunity to criticise the report of the British Association for Counselling. ${ }^{2}$ I totally agree with their criticism of the report. It is of low quality and does not provide reliable evidence on the effectiveness of counselling. However, I was surprised by the fact that the authors did not present reliable evidence that does exist on the topic. The question cannot be left unanswered. We gave an answer to an almost similar question in our article on evidence based medicine. We showed the feasibility of searching for evidence in Medline for practitioners of occupational health. ${ }^{3}$ We elaborated an example of a teacher with symptoms of burnout who wanted to know the best treatment for his condition. Our search resulted in at least one good review and one meta-analysis. ${ }^{45}$ The meta-analysis by van der Klink et al firmly concludes: "stress management interventions are effective and cognitive-behavioural interventions are more effective than the other intervention types". This is in line with the earlier findings of the review by Murphy that we found as well.

From the authors' editorial it can be inferred that they favour interventions such as a reduction of working hours or increasing staff numbers, more than counselling. This does sound sympathetic to me as well and it is in line with the principle of hierarchy of controls, which states that primary prevention is to be preferred to, for example, personal protective equipment. ${ }^{6}$ However, in our case, there is not much evidence that supports such an approach. This is partly due to a lack of studies in the area of organisational interventions. The organisational intervention studies that have been done, however, do not yield a significant effect size. ${ }^{5}$ On the other hand, there seems to be enough evidence to conclude that cognitive behavioural interventions are effective in counterbalancing the effects of stress at work. So, even when only reliable evidence is used, there is still much to support counselling in the sense of cognitive behavioural treatment. In addition, there is a systematic review in the Cochrane Library on counselling in primary care, which concludes that it is associated with a modest improvement in short term outcome compared to "usual care" and not associated with more costs. ${ }^{7}$ Based on this evidence I would not simply reject counselling as ineffective.

This case illustrates that, in occupational health in general, there is a lack of awareness of the existence of evidence on effective interventions. That is the main reason why we are in the process of developing an Occupational Health Field within the Cochrane Collaboration. The Cochrane Collaboration is an international organisation, dedicated to making up-to-date, accurate information about the effects of healthcare readily available worldwide. Have a look at www.cochrane.org for more details.

We hope that, in the near future, the Occupational Health Field will fulfil its promises and will simplify the finding of evidence on occupational health interventions like counselling.

J Verbeek

Coronel Institute for Occupational and Environmental Health, University of Amsterdam, Occupational Health Field, Finnish Institute of Occupational Health, Kuopio, Finland; j.h.verbeek@amc.uva.nl

doi: 10.1136/oem.2003.012138

\section{References}

1 Henderson M, Hotopf M, Wessely S. Workplace counselling. Occup Environ Med 2003:60:899-900 
2 McLeod J. Counselling in the workplace: the facts Rugby. British Association for Counselling and Psychotherapy, 2001.

3 Verbeek JH, van Dijk FJ, Malmivaara A, et al Evidence-based medicine for occupational health. Scand J Work Environ Health 2002;28: 197-204.

4 Murphy LR. Stress management in work settings: a critical review of the health effects. Am J Health Promot 1996;11:112-35.

5 van der Klink JJ, Blonk RW, Schene $A H$, et al. The benefits of interventions for work-related stress. Am J Public Health 2001;91:270-6.

6 Roelofs CR, Barbeau EM, Ellenbecker M, et al. Prevention strategies in industrial hygiene: a critical literature review. AlHA J 2003;64:62-7.

7 Bower P, Rowland N, Mellor C, et al. Effectiveness and cost effectiveness of counselling in primary care. Cochrane Database Syst Rev 2002; CD001025.

\section{Comments on article by Koh and $A w$}

Quoting both dictionary definitions and statutory requirements, Koh and Aw's education article ${ }^{1}$ limits the definition of occupational "health surveillance" to the detection of adverse health effects resulting from occupational exposures. In doing so, they exclude international and national requirements for occupational health and medical surveillance to assess fitness for work.

Looking at the hazard of ionising radiation, international recommendations, ${ }^{2}$ European Directives, ${ }^{3}$ and UK National Legislation ${ }^{4}$ all identify a requirement for surveillance where the primary purpose is an assessment of the individual's fitness for post. Similarly, in considering surveillance of divers, a key element of requirements is an assessment of fitness for work. On a more general level, both in the public and in the occupational setting, systems of health surveillance exist for drivers where it is clearly nonsense to suggest that this is aimed at the detection of adverse effects resulting from time behind the wheel. It is therefore suggested that the authors' conclusion needs to be expanded to identify a requirement for periodic examination of individuals, not only to detect reversible ill health, but also to assess fitness for work.

C Kalman

Salus Occupational Health \& Safety, Centrum Park, Hagmill Road, Coatbridge ML5 4TD, UK Chris.Kalman@laht.scot.nhs.uk

doi: 10.1136/oem.2003.011551

\section{References}

1 Koh D, Aw T-C. Surveillance in occupational health. Occup Environ Med 2003;60:705-10.

2 ICRP. Recommendations of the International Commission on Radiation Protection. Publication 60, 1992.

3 European Union. Basic safety standards for the health protection of the general public and workers against the dangers of ionising radiation. European Union Council Directive 1996/29/ EURATOM, 13 May 1996.

4 The lonising Radiations Regulations 1999 (UK statutory instrument).

\section{BOOK REVIEW}

\section{Tolley's managing stress in the workplace}

Carole Spiers (£60.00). Croydon, UK: LexisNexis UK. ISBN 0-7545-1269-X

"Not another book about workplace stress" emanating in this case, from the "stress industry" would be an understandable reaction. Carole Spiers, the author, unequivocally describes herself as an "occupational stress consultant" and head of the Carole Spiers Group: "International Corporate Well-being Consultants".

She faces up to the implications immediately by asking "Why indeed another book about stress? What makes it different from the others?" Well, this one is intended to be practical and user friendly - a handbook that can sit on your shelf and act as a reference manual to be dipped into whenever required. It is aimed primarily at employers, employees, and their representatives rather than occupational health practitioners or academics; this is not a criticism-many occupational health practitioners will appreciate the way in which the subject of work related stress is assiduously presented in all its complexity.

Far from being all about the practicalities of managing stress in the workplace, there are chapters which go into some detail about the nature of stress, current legislation, and the health and safety framework in the UK and, to some extent, Europe. Naturally there has to be constant reference to health and safety and employment law but also to civil litigation, and here comes one of the problems: very few cases of work induced stress have in fact been litigated and those that have, have not, in many people's view, been very typical. Moreover, this is a fast changing field and the useful synopsis of appeal cases heard in 2002 may soon be out of date on account of impending House of Lords judgements. In another domain, namely identifying current workplace stressors, the template used: Culture, Demands, Control, Relationships, Change, Role, and Support has already been refined by the Health and Safety Executive as more is learned about measuring psychosocial factors at work.

However, the approach taken by the author to understanding the problem is straightforward, accepted by most, practical, and will be useful for people who want to systematise their approach to identifying workplace stressors or measure the effects of stress on an organisation.

There are chapters on bullying, posttraumatic stress, stress and health, and the effects of stress on the individual, whose conclusions will not be accepted by all. There is, unsurprisingly, a chapter on personal stress management strategies which sweeps up much of the advice, good and bad, offered by the self help industry and, to balance it, a chapter on healthy organisations. There is a short chapter on the future of stress.
In 400 pages the author covers most of what there is to know about the wider world of stress and has usefully interwoven a number of relevant themes. I was surprised how little mention was made of the medicalisation of stress-after all most employers receive their first intimation of an employee's stressed state by means by means of a sickness absence certificate signed by a general practitioner. This issue is only cursorily examined in chapter 10 . I also failed to recognise many of the examples of stressed individuals which populate the book. They are all real cases, but where are the people with relatively undemanding jobs, beset by social problems, domestic difficulties, and unhealthy habits referred by harassed middle managers? It is often a toss up to know who will "go off with stress" first. I am not sure that this book is very enlightening about how to manage those people and how to prevent the seemingly inevitable slide of such individuals into resentment, long term sickness absence, and, eventually, Incapacity Benefit.

There does, also, seem to be an emphasis on larger organisations and not much about the dynamics within small and medium sized enterprises (where most people work these days), which are different.

The book does, however, deserve to be "dipped into" because there is a wealth of descriptive material on which to build.

D Snashall

\section{NOTICE}

\section{8th ICOH International Congress on Occupational Health}

The 28th ICOH International Congress on Occupational Health will be held in Milan, Italy, 11-16 June 2006.

Further information:

www.icoh2006.it

Tel: +39 0250320110; fax: +39025032011

Email: sabrina.braiati@unimi.it

\section{CORRECTION}

doi: 10.1136/oem.2002.006239corr l

With reference to the paper "Risk of selected birth defects by maternal residence close to power lines during pregnancy" (Blaasaas KG, Tynes T, Lie RT. Occup Environ Med 2004;61:174-6), the authors state:

"The total number of births inside the specified corridor given as 128680 in the Results was wrong. We verified, however, that only 42223 pregnancies were completed on specific addresses inside the corridor. These 42223 births represented the cohort from which we identified the 465 cases and selected 930 controls. This should have been specified in the paper. The error gave a wrong impression of the prevalence of defects but had no implications for the results of the paper." 